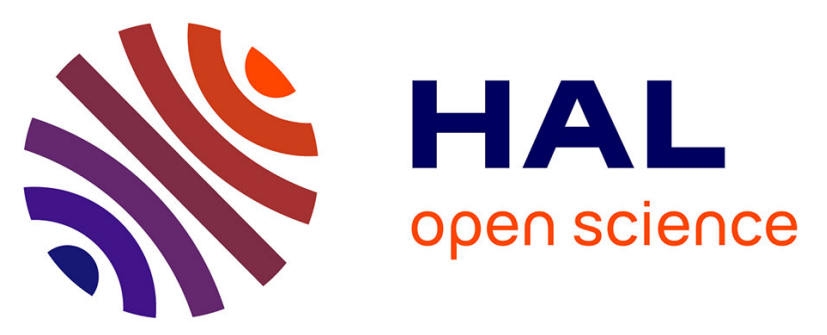

\title{
Structural, Micromechanical and Tribological Analyses of Electrodeposited Nickel-Graphite Coatings with Different Fractions of Graphite Microparticles
}

Dorra Trabelsi, Manel Zouari, Mohamed Kharrat, Mahe Dammak, Marielle Eyraud, Florence Vacandio

\section{To cite this version:}

Dorra Trabelsi, Manel Zouari, Mohamed Kharrat, Mahe Dammak, Marielle Eyraud, et al.. Structural, Micromechanical and Tribological Analyses of Electrodeposited Nickel-Graphite Coatings with Different Fractions of Graphite Microparticles. Transactions of the Indian Institute of Metals, 2018, 10.1007/s12666-018-1301-4 . hal-03541066

\section{HAL Id: hal-03541066 https://hal.science/hal-03541066}

Submitted on 24 Jan 2022

HAL is a multi-disciplinary open access archive for the deposit and dissemination of scientific research documents, whether they are published or not. The documents may come from teaching and research institutions in France or abroad, or from public or private research centers.
L'archive ouverte pluridisciplinaire HAL, est destinée au dépôt et à la diffusion de documents scientifiques de niveau recherche, publiés ou non, émanant des établissements d'enseignement et de recherche français ou étrangers, des laboratoires publics ou privés. 


\title{
Structural, Micromechanical and Tribological Analyses of Electrodeposited Nickel-Graphite Coatings with Different Fractions of Graphite Microparticles
}

\author{
Marielle Eyraud $^{2} \cdot$ Florence Vacandio $^{2}$ \\ 1 Laboratory of Electromechanical Systems (LASEM), \\ National Engineering School of Sfax, University of Sfax, \\ Soukra Road, Km 3.5, PO Box 1173, 3038 Sfax, Tunisia \\ 2 Laboratory "Divided Materials, Interface, Reactivity, \\ Electrochemistry" (MADIREL), Aix-Marseille University, \\ Marseille, France
}

Dorra Trabelsi $^{1} \cdot$ Manel Zouari $^{1} \cdot$ Mohamed Kharrat $^{1} \cdot$ Maher Dammak $^{1}$.

\begin{abstract}
Nickel-graphite composite coatings were electrodeposited on a steel substrate from typical watts bath and with specific operating conditions for different weight fractions of graphite microparticles. The weight percentage of particles in coatings and the microstructure were studied, respectively, by atomic absorption, scanning electron microscope and X-ray diffraction. The influence of graphite fraction on roughness and microhardness were also investigated. It was found that roughness increases with the increase of particle content while microhardness decreases. The tribological response was examined against high chromium steel ball using linear reciprocating tribometer. The results indicated that the friction coefficient decreases when graphite content increases. This was ascribed to the development of tribo-layer on the wear track and transfer film on the counterface. However, it was found that the improvement of wear resistance was obtained until an optimal value of graphite concentration, which provided the best condition that promoted the tribo-layer stability and maintained the matrix integrity.
\end{abstract}

Keywords Electrodeposition · Nickel · Micrographite · Composite $\cdot$ Friction $\cdot$ Wear

\section{Introduction}

In recent years, huge progresses have been made in the formulation of solid lubricant composite coatings for a large range as far as industrial applications are concerned. These composite coatings are intended to provide the highest level of performance in terms of self-lubricity and wear reduction as well as corrosion-resistance. Self-lubricating coatings have been the interest of many researchers [1]. They are used to control friction and wear, where conventional lubricants cannot afford the desired level of performance and durability under severe application conditions [2]. Many deposition procedures of composite coatings are used constantly such as plasma, physical vapor deposition (PVD), chemical vapor deposition (CVD), ion implantation and electrodeposition [3, 4]. Among these procedures, electrodeposition is one of the most suitable one which can display a compromise between simplicity and economic concerns. It is considered as the major deposition technique that is industrially used for the co-deposition of both metal and particles into composite coatings. In fact, the problem of stable suspension of particles in the electrodeposition solution is generally overcome by the addition of suitable surfactant [5]. The latter also plays a fundamental role in the reduction of hydrogen embrittlement in the coatings, minimizing particles agglomeration and enhancing particles co-deposition [6]. Cetyltrymethyl ammonium bromide (CTAB) and sodium dedocyl sulfate (SDS) are frequently employed as surfactants [7, 8]. Plated nickel $(\mathrm{Ni})$ has been widely used as a coating matrix owing to its high brightness, hardness and corrosion resistance ability. Moreover, as illustrated by recent studies, the inclusion of fine lubricating particles (such as graphite, polytetrafluoroethylene (PTFE), molybdenum disulfide $\left(\mathrm{MoS}_{2}\right)$, etc. [9-11]) or hard particles (such as titanium carbide (TiC), alumina $\left(\mathrm{Al}_{2} \mathrm{O}_{3}\right)$, Zinc 
Oxide ( $\mathrm{ZnO})$, etc. $[12,13])$ into nickel matrix can enhance its mechanical and tribological properties [14]. For example, Goral et al. [15] have pointed out that the addition of aluminum oxide $\left(\mathrm{Al}_{2} \mathrm{O}_{3}\right)$ with a concentration of $80 \mathrm{~g} / \mathrm{L}$ of $\mathrm{Al}_{2} \mathrm{O}_{3}$ in the electrolytic bath exhibit a three times lower wear rate than the pure $\mathrm{Ni}$ coatings. Furthermore, Lekka et al. [16] have demonstrated that the presence of microand nano sized silicon carbides $(\mathrm{SiC})$ particles in the $\mathrm{Ni}$ matrix leads to a decrease in the friction coefficient to 63 and $88 \%$ at $25^{\circ}$ and $300{ }^{\circ} \mathrm{C}$ respectively. Several others researches have been focused on the study of $\mathrm{Ni}$-graphite composite coatings, thanks to the economic and powerful characteristics of graphite particles [17, 18]. Thus, many of them were interested in the study of the weight fraction of graphite influence in the properties of Ni-graphite composite coatings. Wu et al. [19] have characterized the graphite-Ni composite coatings obtained by automatic brush plating. They have found that the graphite content largely affects the roughness, the friction coefficient and the wear rate of $\mathrm{Ni}$-graphite coatings. Whereas, $\mathrm{He}$ et al. [20] have focused on the study of the influence of graphite particles concentration on the surfaces morphology of Ni-graphite coatings obtained by electrodeposition from sulfamate bath. Further, Zhao et al. [9] have illustrated the influence of graphite concentration on the mechanical and tribological behaviors of Ni-graphite coatings elaborated by electrodeposition from sulfamate bath. They have found that the wear mechanism for these composite coatings is a delaminating wear, characterized by subsurface crack nucleation. Indeed, when the crack attains a critical length and propagates to the surface, delamination starts and the wear becomes catastrophic [21]. One of the possible reasons for this wear mechanism is the internal stress. Indeed, the addition of particles may change the state of internal stress due to the mismatch of lattice parameters, the distortions or the cracks between the particles [22]. The present study investigates the effect of graphite content on the structural, micromechanical and tribological properties of nickelgraphite coating obtained by electrodeposition from watts bath with specific parameters, extracted from previous study [23] and minimize the internal stress of coatings. These parameters have been used in order to enhance mechanical and tribological behaviors of $\mathrm{Ni}$-graphite coatings.

\section{Materials and Methods}

\subsection{Composite Coatings Preparation}

The electrolyte used in the plating of Ni-graphite composite coatings was watts bath. The electrochemical bath components consisted of nickel sulfate (supplied by Sigma
Aldrich) as Ni source, boric acid as buffer solution and nickel chloride (supplied by Sigma Aldrich) to prevent the anode from passivity. The bath composition and operating conditions are listed in Table 1 . The weighted graphite particles in the range of 7-11 $\mu \mathrm{m}$ (supplied by Alfa Aesar) were used as a solid lubricant. Meanwhile, in order to enhance the electrostatic adsorption of suspended particles on the cathode surface, the surfactant such as sodium dodecyl sulfate (SDS) was added to the solution. All bath ingredients were agitated for $2 \mathrm{~h}$ by magnetic stirring. Subsequently, the sonication process had served for $30 \mathrm{~min}$ to provide homogeneous dispersion and to prevent the agglomeration of the particles. The operating conditions in terms of $\mathrm{pH}$ and current density were chosen from a previous research [23] in which the aim was to minimize the internal stresses. Actually, electroplating parameters such as current density, $\mathrm{pH}$, bath temperature, and additive concentration strongly affect the internal stress [24]. They directly affect the hydrogen codeposition, the overpotential of deposition and the lattice misfit, which are among the suggested theories responsible for internal stresses in the coatings [25]. Generally, increasing the current density leads to the increase in the internal stresses [26]. However, the effect of $\mathrm{pH}$ on the internal stresses depends on the bath composition. For example, it has been recommended that $\mathrm{pH}$ should be less than 5 for watts bath [26] while, internal stresses attain the minimum at $\mathrm{pH}=4$ and increase below 4 in sulfamate bath [27]. The temperature of the bath also affects the internal stresses: the rise in the temperature of the electroplating bath leads to the decrease of internal stresses in most cases [28].

Carbon sheet was used as anode and cathode was made using mild steel E24 $(0.17 \% \mathrm{C}, 1.4 \% \mathrm{Mn}, 0.045 \% \mathrm{~S}$, $0.045 \% \mathrm{P}$ and $98.34 \% \mathrm{Fe}$ ) with the dimensions of $30 \times 20 \times 15 \mathrm{~mm}^{3}$ as a substrate. The active surface area was $450 \mathrm{~mm}^{2}$ and the remaining surfaces were hidden with adhesive tape. Before electrodeposition, the active surface area of substrate was mechanically polished with abrasive paper, degreased by $\mathrm{NaOH}$ solution with $\mathrm{pH}=11$ and etched by means of $10 \% \mathrm{H}_{2} \mathrm{SO}_{4}$ for $1 \mathrm{~min}$. After each preparation step, the substrate was rinsed with distilled water so as to completely remove the residuals of each stage.

\subsection{Characterization Techniques}

Atomic absorption technique was used to evaluate the graphite phase content into the $\mathrm{Ni}$ composite coating for each of the considered concentration of graphite particles in the electrochemical bath $(0 \mathrm{~g} / 1,1 \mathrm{~g} / \mathrm{l}, 5 \mathrm{~g} / \mathrm{l}, 10 \mathrm{~g} / \mathrm{l}$, and $20 \mathrm{~g} / \mathrm{l})$. The mass of the deposits was determined by a balance of precision equal to $0.01 \mathrm{mg}$ at the first step. Subsequently the coated substrate was put in a 
Table 1 Bath composition and operating conditions

\begin{tabular}{|c|c|c|c|}
\hline \multicolumn{2}{|c|}{ Bath composition $(\mathrm{g} / \mathrm{l})$} & \multicolumn{2}{|l|}{ Operating conditions } \\
\hline $\mathrm{Ni} \mathrm{SO} \mathrm{SO}_{4}-6 \mathrm{H}_{2} \mathrm{O}$ & 270 & Temperature $\left({ }^{\circ} \mathrm{C}\right)$ & 50 \\
\hline $\mathrm{Ni} \mathrm{Cl}{ }_{2}-6 \mathrm{H}_{2} \mathrm{O}$ & 50 & $\mathrm{PH}$ & 2 \\
\hline $\mathrm{H}_{3} \mathrm{BO}_{3}$ & 35 & Current density $\left(\mathrm{A} / \mathrm{dm}^{2}\right)$ & 4.8 \\
\hline Graphite & $0-1-5-10-20$ & Stirring speed (rpm) & 700 \\
\hline \multirow[t]{4}{*}{ SDS } & $20 \mathrm{mg} / \mathrm{g}$ of graphite & Plating time (min) & 60 \\
\hline & & Electrolyte volume(ml) & 250 \\
\hline & & Anode & Carbon \\
\hline & & Cathode & Mild steel \\
\hline
\end{tabular}

concentrated nitric acid $\left(\mathrm{HNO}_{3}\right)$. This solvent dissolved the nickel without attacking the steel according to the norm NF A 91,101 [29]. After complete dissolution of $\mathrm{Ni}$, (i.e when the residual mass was equal to the mass of the substrate before electrodeposition), the steel substrate was picked up and the obtained solution $\left(\mathrm{HNO}_{3}+\right.$ Nickel $)$ was heated up to $100{ }^{\circ} \mathrm{C}$ until $\mathrm{HNO}_{3}$ got fully evaporated. Thereafter, distilled water was added to the solution that was heated to $100{ }^{\circ} \mathrm{C}$ in order to rinse the sample from residual acid. After its full evaporation, $50 \mathrm{ml}$ of distilled water was added. Then, the obtained solution was filtered to remove the graphite particles. Finally, it was examined by atomic absorption to know the weight percentage of nickel in this solution. Therefore, the weight percentage of graphite was also deduced. SEM and XRD were used to investigate the coating's surface morphologies as well as the wear traces. Cross sections of substrates were prepared and analyzed by optical microscope to determine the thickness of the coatings. The roughness of various coatings and wear volume were investigated by tactile profilometer. The surface roughness parameter Ra was used for analysis and was measured over a tracing length of $12 \mathrm{~mm}$. Micro hardness of various coatings were measured by Vickers indentation at a load of $1000 \mathrm{~g}$.

The friction and wear test were carried out using a linear reciprocating tribometer designed in our laboratory (Fig. 1). A ball on plane contact configuration was utilized. High chromium steel (100Cr6) was the material of the counter body, having a diameter of $15 \mathrm{~mm}$ and a surface roughness $\mathrm{Ra}$ of 0.02 . Preceding each friction test, the coating surface as well as the ball surface were rinsed with ethanol. The apparatus allowed contact between the steel ball and the coating surface under a constant normal load. Tangential cyclic motion was then applied to the coated specimen. A load cell located between the coated specimen and its holder allowed to measure the tangential force. The output of this load cell was continually stored using a data acquisition system. Normal load, tangential motion amplitude and frequency were adjusted to $6 \mathrm{~N}, 7.5 \mathrm{~mm}$ and

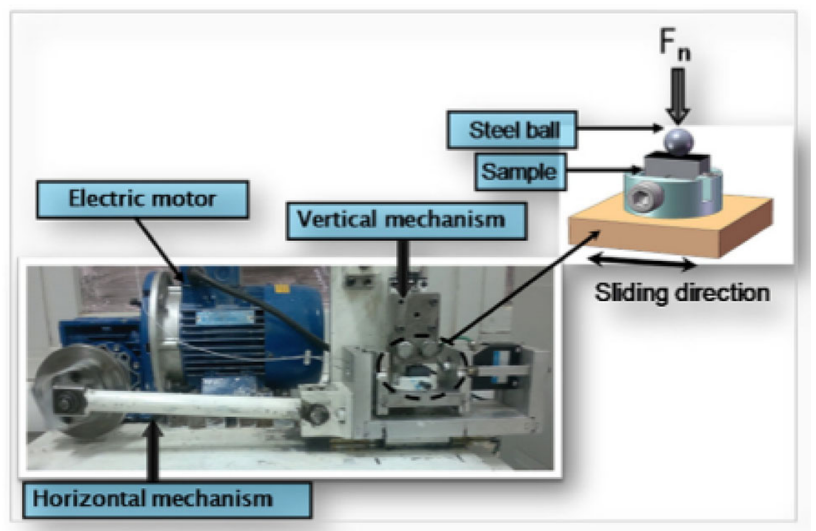

Fig. 1 Reciprocating friction and wear apparatus

$1 \mathrm{~Hz}$, respectively. The wear tests were performed at room temperature $\left(25^{\circ} \mathrm{C}\right)$ and with a relative humidity of $55 \pm 5 \%$. Following each friction test, wear track on the coating surface was observed by SEM and worn surface of the spherical counter body was observed by optical microscope $(\mathrm{OM})$. The wear volume was measured on the basis of wear track profile developed by a tactile profilometer over a tracing length of $4 \mathrm{~mm}$ in a direction perpendicular to the sliding direction (Fig. 2).

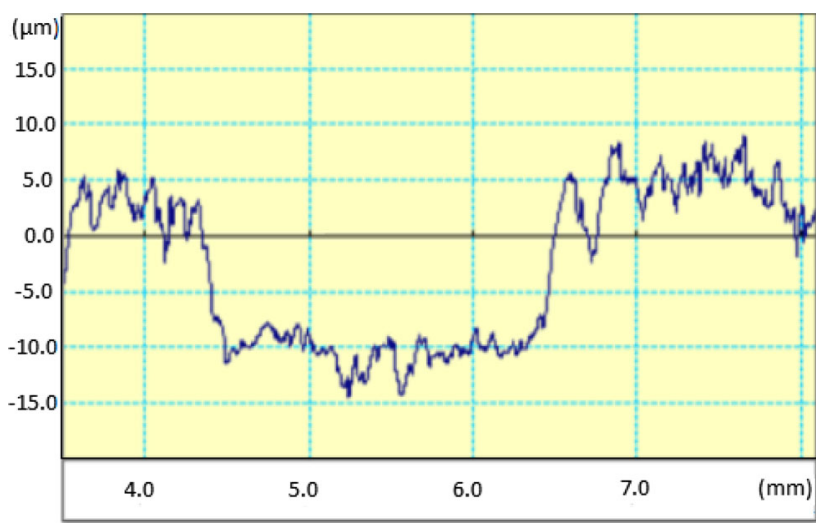

Fig. 2 Wear track profile 


\section{Results and Discussion}

\subsection{Microstructures and Morphologies of Coatings}

\subsubsection{Graphite Weight Fractions}

The weight percentage of graphite particles in the $\mathrm{Ni}$ composite coating as a function of their concentration in the electrolytic bath is shown in Fig. 3. The incorporation of graphite particles into the Ni matrix can be explained by the codeposition mechanism of inert particles from electrolyte bath. According to Wasekar et al. [30] and in analogy to Guglielmi's simplified model for composite electrodeposition [31], during first stage of addition to the metal ions, there is the adsorption of $\mathrm{Ni}$ on the surface of graphite particles. In the second step, migration of graphite particles with ionic cloud to the cathode surface through diffusion layer takes place. Here these particles get adsorbed thereby loosing hydrated shell by electron transfer reaction. Finally, the $\mathrm{Ni}$ atoms get incorporated into crystal lattice surrounding the graphite particles. Thus, a graphite particle gets encapsulated in Ni matrix. A higher concentration of graphite particles in plating bath enhances the adsorption rate leading to a higher volume percentage of the codeposited graphite particles [14]. However, the capturing capacity of the growing metal does not increase simultaneously with the increase of graphite concentration [32] and when the amount of graphite particles exceed the maximum amount of saturation state, an elastic collision of particles inside the electrolyte take place, leading to particles agglomeration and thereafter a shielding effect for particles codeposition can take place [33]. Therefore in this study, the amount of particles is almost constant after

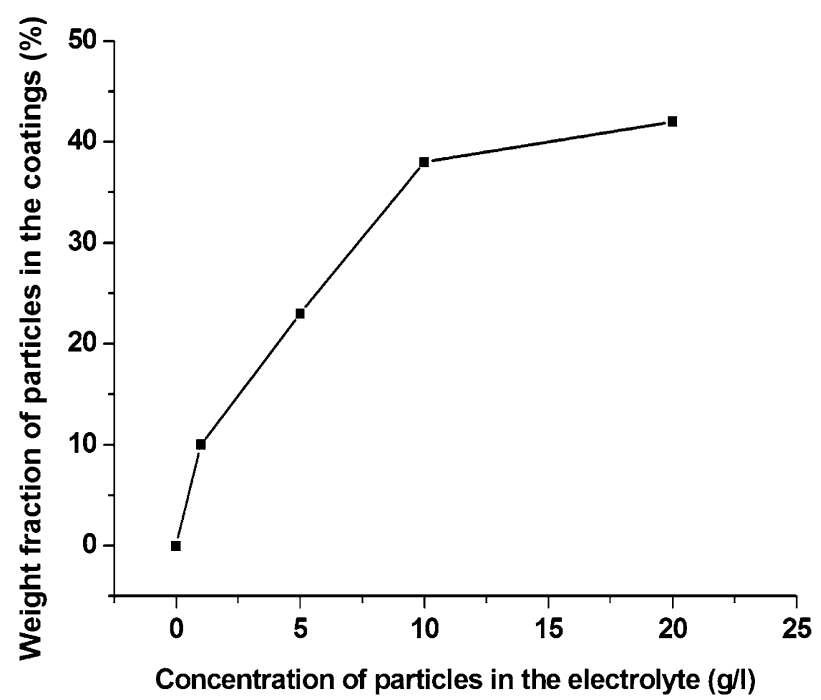

Fig. 3 Weight fraction of graphite particles in coatings versus graphite concentration in electrolytic bath exceeding a boundary concentration of particles in the electrolytic bath $(10 \mathrm{~g} / \mathrm{l})$. This result is similar to that found by Wang et al. [22] for $\mathrm{Al}_{2} \mathrm{O}_{3}-\mathrm{Cu}(\mathrm{Sn})$ composite and Ghorbani et al. [34] for graphite-brass composite coatings.

\subsubsection{Microstructures}

SEM micrographs exhibiting surface morphologies of pure $\mathrm{Ni}$ and $\mathrm{Ni}$-graphite composite coatings filled with different weight fractions of graphite solid lubricant (10, 23, 38, $42 \mathrm{wt} \%$ ) are shown in Fig. 4. The micrograph of pure Ni coating reveals a regular pyramidal structure with uniform grain size and smooth surface compared to the surface of $\mathrm{Ni}$ matrix filled with graphite particles. Indeed, it seems that the graphite particles with irregular shapes marked in the SEM micrographs as a light phase, are homogeneously dispersed into the Ni matrix.

The XRD diagram of pure nickel and Ni-graphite composite layers which contain $23 \mathrm{wt} \%$ of graphite particles are presented in Fig. 5. As can be seen, the pure Ni pattern displays typical peaks of Nickel having a face centered cubic structure (FCC) and exhibits a strong (200) reflection peak that reveals the preferred orientation. In fact, the growth of pure nickel coatings is carried out by nucleation on the substrate surface followed by columnar growth of grains (perpendicular to the substrate surface) in (200) preferred crystallographic direction. These grains end up at the coating surface, leading to pyramidal structure [35]. The addition of graphite microparticles results in the change of the predominant reflection peak to (111) which, in turn, is the most intense peak in the XRD pattern from standard randomly oriented nickel [36]. This denotes that $\mathrm{Ni}$-graphite composite coatings have more random grain structure, and subsequently, a rougher surface texture. A similar observation has been revealed by different authors in their studies of Ni composite coating. Srivastava et al. [37] inferred that the change of preferred orientation with the incorporation of nano $\mathrm{SiC}$ particles is attributed to the change of the surface morphology of Ni grains from dense spherical smooth surface to rough nodular surface.

\subsubsection{Morphologies}

Cross sections have been prepared on the considered coatings and observed by OM (Fig. 6). The thickness seems to be constant (about $50 \mu \mathrm{m}$ ) for the different coatings (Table 2). A slight decrease can be observed for coatings containing $42 \%$ graphite $(40 \mu \mathrm{m})$. It seems that, at high concentration of particles, the graphite particles play the role of physical barriers to grain growth and decelerate the growth rate; therefore, thinner composite coating can be seen. This result has also been found by Borkar et al. 


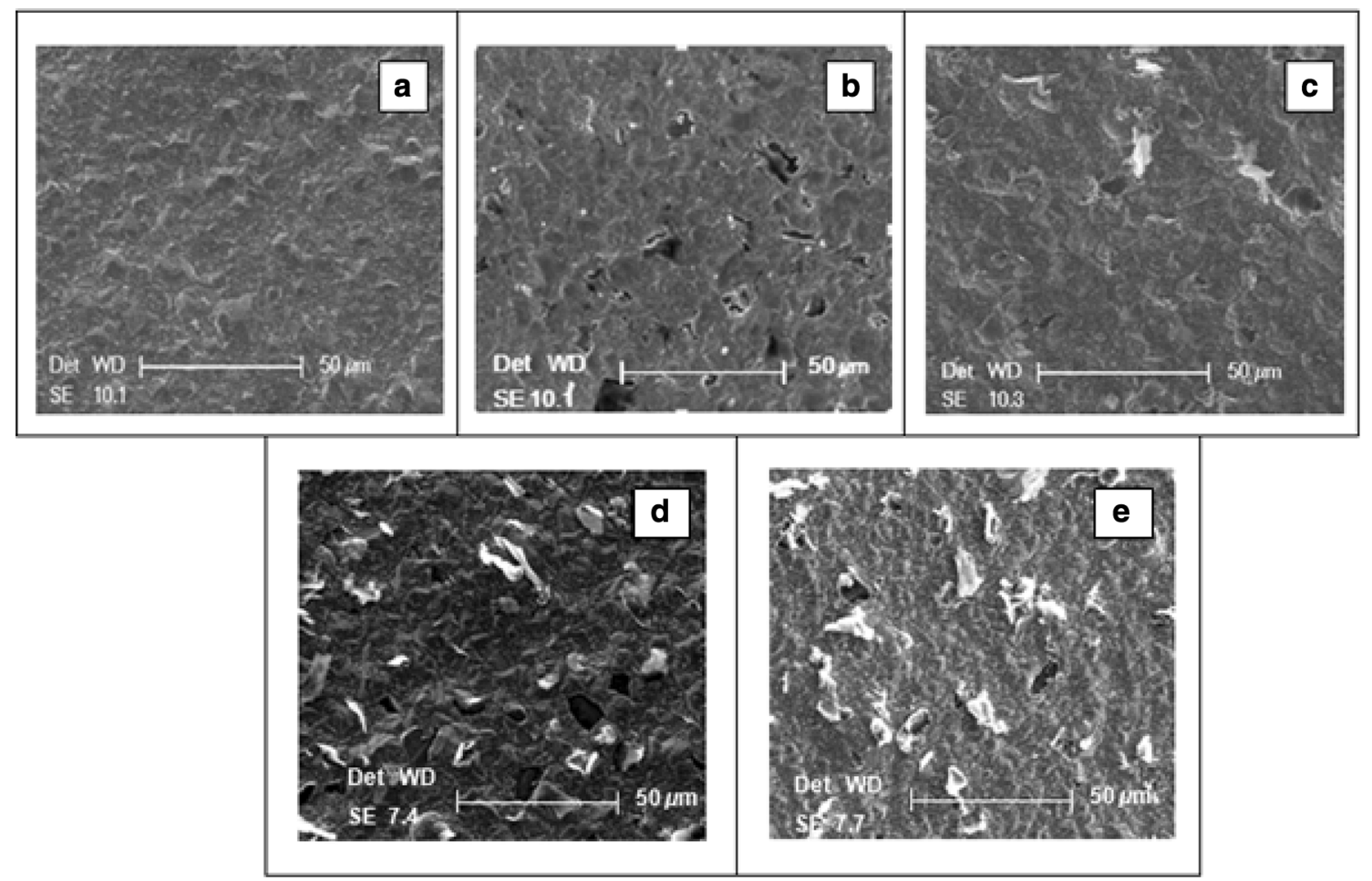

Fig. 4 SEM micrographs of Ni-graphite composite coatings with different weight fraction of graphite a $0 \%$, b $10 \%$, c $23 \%$, d $38 \%$, e $42 \%$

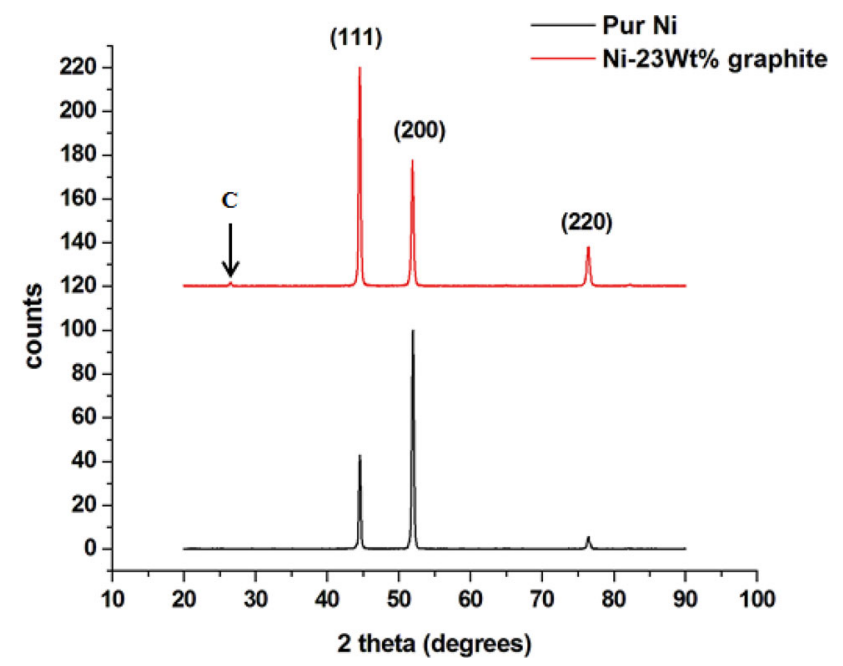

Fig. 5 XRD of Pure Ni and Ni-graphite coating with 23 wt $\%$ of graphite

[38] while studying the effect of $\mathrm{Al}_{2} \mathrm{O}_{3}$ content on the microstructure of nickel composite coatings.

\subsubsection{Surface Roughness}

The evolution of surface roughness $\mathrm{Ra}$ with graphite content in the coating is presented in Fig. 7. It can be seen that the particle content in the coating strongly influences the surface roughness. The values of $\mathrm{Ra}$ are in the range of
$0.8 \mu \mathrm{m}$ for pure $\mathrm{Ni}$ coating to $2.4 \mu \mathrm{m}$ for composite coating containing $42 \mathrm{wt} \%$ graphite. This increase of surface roughness with the increase of wt\% of particles seems to be caused by the random oriented texture (as explained in the previous paragraph) and more collision of particles when their amount increases in the bath. Ghorbani et al. also found similar results for the surface roughness of electrodeposited bronze-graphite [39].

\subsection{Micromechanical and Tribological Behaviors of Ni-Graphite Coatings}

\subsubsection{Microhardness}

Figure 8 illustrates the effect of weight fraction of graphite in the composite coating on the microhardness of the considered coatings. The microhardness presents a strong drop between 0 and 10 wt $\%$ of graphite. Subsequently, the surface microhardness of Ni composite coatings displays a quasi-linear decrease as the graphite particle's amount in the Ni matrix increases. This decrease is attributed to the sliding and soft nature of graphite particles. Hence, they are easily deformed under a contact stress: the increase of graphite fraction in the composite coatings leads to the decrease in the capability of anti-plastic deformation that brings in lower microhardness of the composite coatings [40]. 


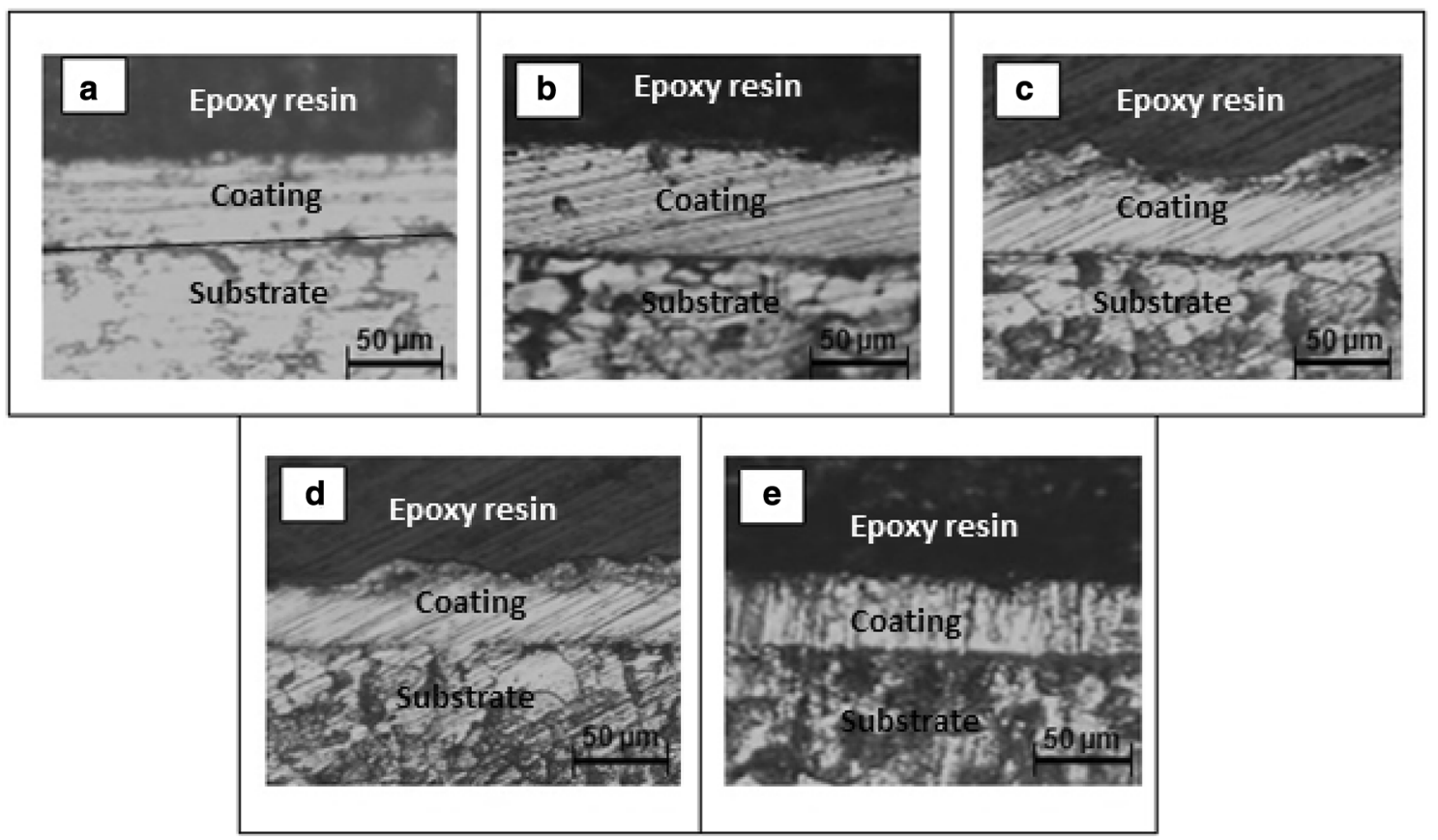

Fig. 6 Cross section of Ni-graphite composite coatings filled with different weight fraction of graphite: a $0 \%$, b $10 \%$, c $23 \%$, d $38 \%$, e $42 \%$

Table 2 Thickness of Ni composite coatings filled with different weight fraction of graphite

\begin{tabular}{llllll}
\hline Coatings & $\mathrm{a}$ & $\mathrm{b}$ & $\mathrm{c}$ & $\mathrm{d}$ & $\mathrm{e}$ \\
\hline Thickness $(\mu \mathrm{m})$ & $49.35 \pm 2.3$ & $53.71 \pm 3.4$ & $50.61 \pm 2.8$ & $47.02 \pm 3.7$ & $40.42 \pm 1.8$ \\
\hline
\end{tabular}

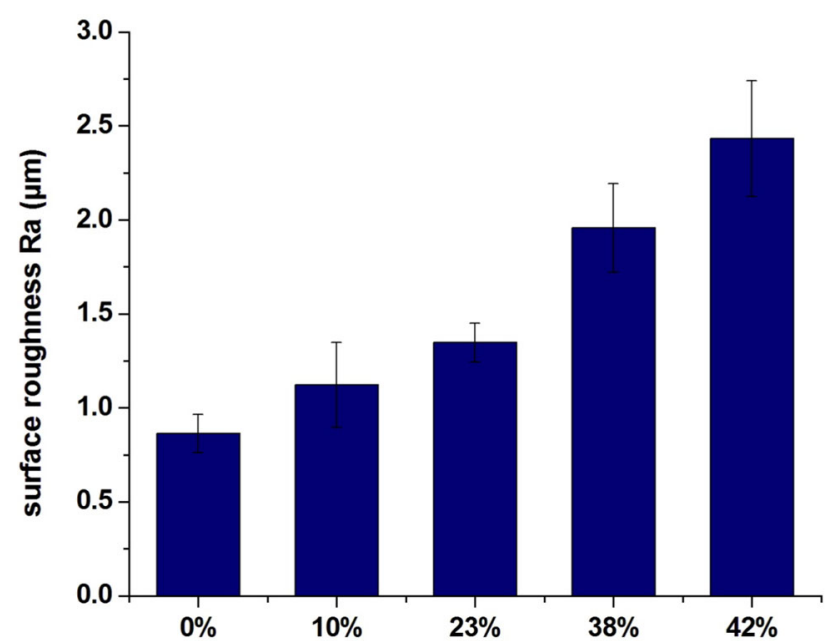

Weight fraction of graphite in Nicomposite coatings

Fig. $7 \mathrm{Ni}$-graphite composite coatings roughness versus different weight fraction of graphite

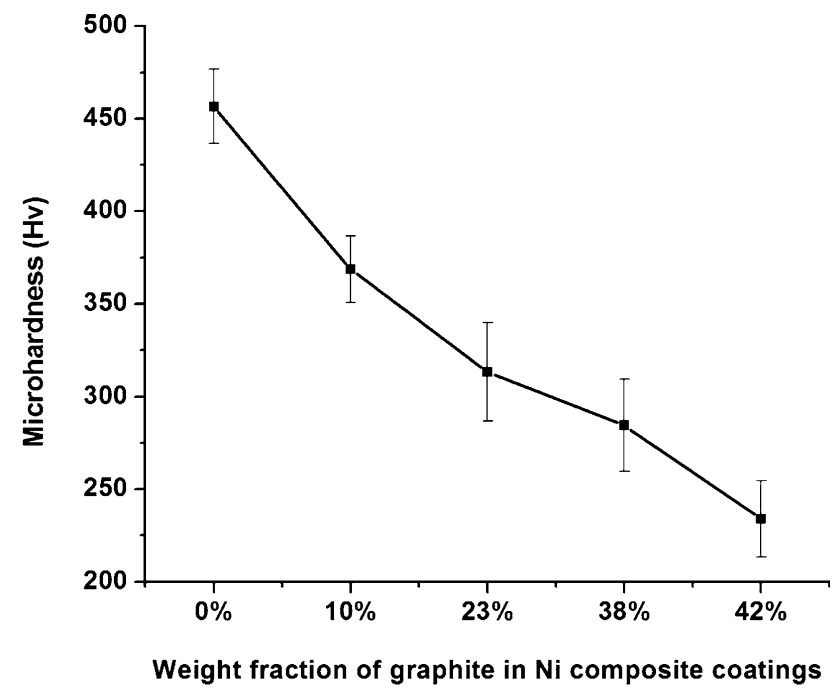

Fig. 8 Microhardness of Ni-graphite composite coatings with different weight fraction of graphite

\subsubsection{Friction Coefficient}

This section highlights the evolution of friction coefficient of $\mathrm{Ni}$ composite coatings, filled with different weight 
fractions of graphite particles, during 2000 sliding cycles as illustrated in Fig. 9. For all coatings, the friction coefficient increases with the number of sliding cycles during the running-in stage and stabilizes afterwards to a steady state value. Figure 10 presents the effect of the graphite weight fraction in the Ni coatings, on the stabilized value of the coefficient of friction (COF) after 2000 sliding cycles. COF for $\mathrm{Ni}$-graphite composite coatings are much reduced compared to the one for pure nickel coating. Hence, the COF value reaches 0.15 for the coating containing the highest amount of graphite used in the present work (42 wt\%). Indeed, an easy slippage takes place between the layers of graphite due to its hexagonal structure. Accordingly, an adherence of graphite particles to the worn surface as well as formation of solid self-lubricant layer is shown on the wear track. Thereupon, the thickness of this layer increases with the increase of graphite content and the metal-metal contact is changed into the graphite filmmetal contact [40]. By an EDX technique, Tang et al. [18] has proved the formation of tribofilm composed of mainly graphite, on the worn surface of $\mathrm{Ni}$-graphite coating deposited by supersonic atmospheric plasma spraying system during the reciprocating sliding friction process.

Furthermore, the rate of COF decrease is obviously lowered beyond $38 \mathrm{wt} \%$ graphite. For this graphite content, the performances of the tribofilm are quite saturated, and no more additional graphite particles are required to reduce frictional interactions between the first contacting bodies, which accords well with the results found by Zhao et al. [9] while, Nickchi et al. [41] found that friction coefficient decreases with the increase in the micro graphite content in the bronze layer, whereas, friction coefficient increases with the increase in nano graphite content in the bronze layer.

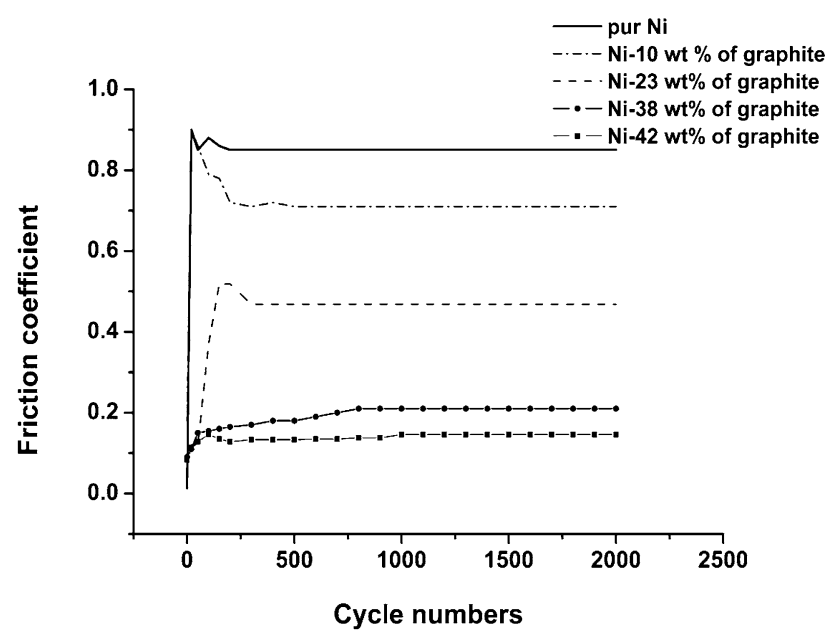

Fig. 9 Friction coefficient trends of Ni-graphite composite coatings filled with different weight fraction of graphite

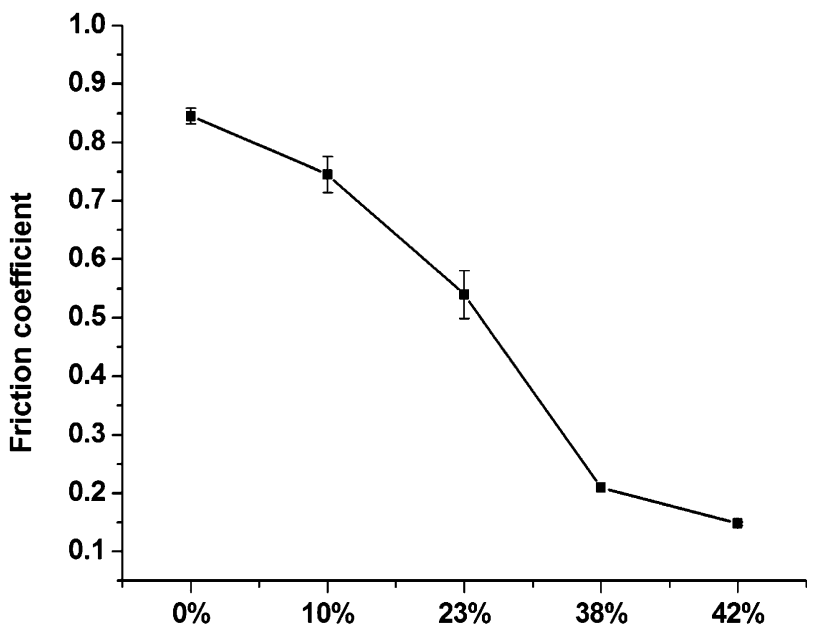

Weight fraction of graphite in Ni composite coatings

Fig. 10 Evolution of stabilized value of friction coefficient versus different weight fraction of graphite in Ni coatings

\subsubsection{Wear Behavior}

Figure 11 reveals the wear volume loss of $\mathrm{Ni}$ composite coatings versus different graphite fractions. It can be noted that the wear volume decreases upto $38 \mathrm{wt} \%$ of graphite particles and then it increases slightly. The initial reduction of wear volume loss as the graphite wt $\%$ increases can be explained by the ability of graphite particles to form a layer of soft wear debris (third body) which covers the wear track on the coated sample. It also forms a thin transfer film mainly composed of graphite that strongly adheres to the spherical counterface, resulting in a lower friction between the contacting solids. When the graphite wt $\%$ exceeds $38 \%$, the particles smash the continuity and uniformity of

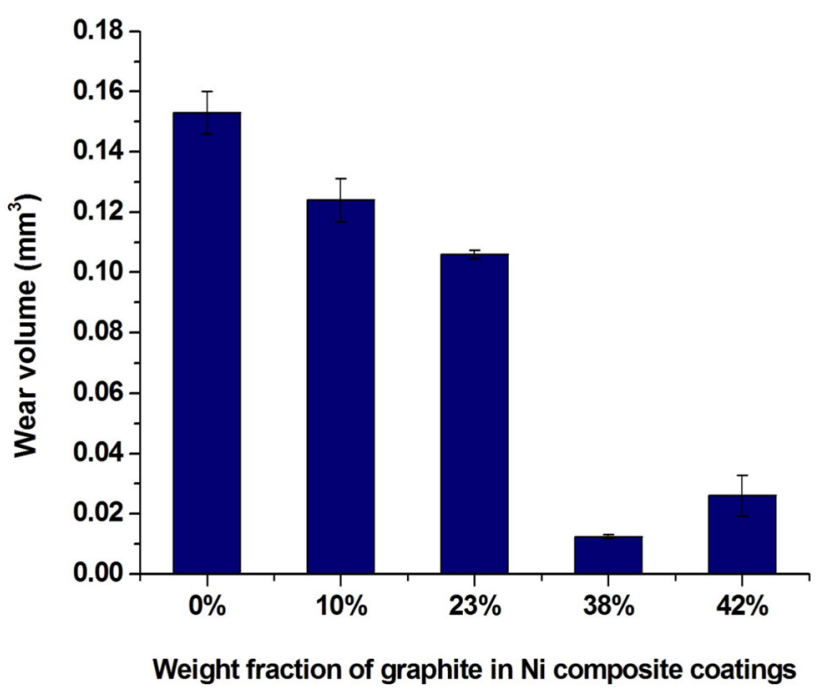

Fig. 11 The evolution of wear volume loss with weight fraction of graphite in $\mathrm{Ni}$ coatings 
the matrix and then result in weakness and fragility of composite coatings. Thus, the wear volume loss increases immensely for coatings with graphite amount equal to $42 \mathrm{wt} \%$. Hence, $38 \mathrm{wt} \%$ of graphite corresponds to the optimal graphite concentration that provides the best condition to promote the solid lubricant layer stability and to maintain the $\mathrm{Ni}$ matrix integrity.

Figure 12 illustrates the SEM micrographs of worn surfaces of Ni-graphite composite coatings after 2000 sliding cycles. As noted for the pure Ni coatings (Fig. 12a), the wear track is deep with some plastic grooves, clear adhesive spalling pits and, indeed, some areas of massive peelings. The addition of $10 \mathrm{wt} \%$ of graphite is still insufficient to improve the wear resistance of $\mathrm{Ni}$ composite coatings (Fig. 12b) and the same wear mechanisms as for the pure Ni coatings are found. Thus, the amount of lubricating particles is not enough to form a continuous third body layer [40]. Therefore, the addition of $10 \mathrm{wt} \%$ of graphite particles does not have a significant effect on the wear process. The incorporation of $23 \mathrm{wt} \%$ of graphite solid lubricant particles in Ni coating (Fig. 12c) leads to a smoother wear scar with fewer and smaller adhesive craters. This can be allocated to the formation of a third-body layer on the whole surface contact during the sliding process. Nonetheless, some grooves are clearly visible, indicating that more severe plastic deformation has taken place. Figure $12 \mathrm{~d}$ illustrates the micrographs of worn surface of Ni coatings containing $38 \mathrm{wt} \%$ of graphite particles. As shown, the wear scar is smooth and straight with little scratches. It seems that with $38 \mathrm{wt} \%$ fraction of graphite added to the $\mathrm{Ni}$ coating, a self-lubricating $\mathrm{Ni}$ graphite is obtained, and the wear resistance of coating is greatly enhanced. With the high graphite fraction (42 wt\%), a wide wear track with some plastic grooves and spalling pits reappears (Fig. 12e). This result can be accounted for by the huge decrease of microhardness of the corresponding coating. Eventually, the loose particles are easily carried out. These snatch particles act as abrasive particles in the contact zones, which, in turn, are considered to harm the transfer film and bring severe abrasive wear [42]. It can be clearly seen that the use of specific operating conditions during the coating process (a current density of $4.8 \mathrm{~A} / \mathrm{dm}^{2}$, a pH of 2 and a coating thickness of $50 \mu \mathrm{m}$ ), like those suggested by Güler et al. [23], largely affects the wear behavior of the Ni-graphite coating. In fact, these specific conditions, which are found to minimize the level of internal stresses, have discarded the catastrophic delaminating wear mechanism found by Zhao et al. [9] for electrodeposited Ni-graphite composite coatings.

Optical micrographs of steel ball worn surfaces, after 2000 sliding cycles, are shown in Fig. 13. Abrasive striations are obvious on the worn surface of the counterface rubbing against pure Nickel (Fig. 13a). Figure 13b exhibits the formation of a discontinuous transfer film on the worn surface of the steel ball in case of coating containing $10 \mathrm{wt} \%$ of graphite. Besides, abrasive striations are still visible. Hence, the addition of graphite particles in coatings leads to the development of a transfer film on the counterface causing a decrease of COF and wear volume. The increase in \%wt of graphite particles in coatings leads to an expansion of the transfer film to cover most of the worn surface of the counterface for $\mathrm{Ni}-23 \mathrm{wt} \%$ of graphite coating (Fig. 13c) and to totally cover the worn surface of the counterface for $\mathrm{Ni}-38 \mathrm{wt} \%$ of graphite coating
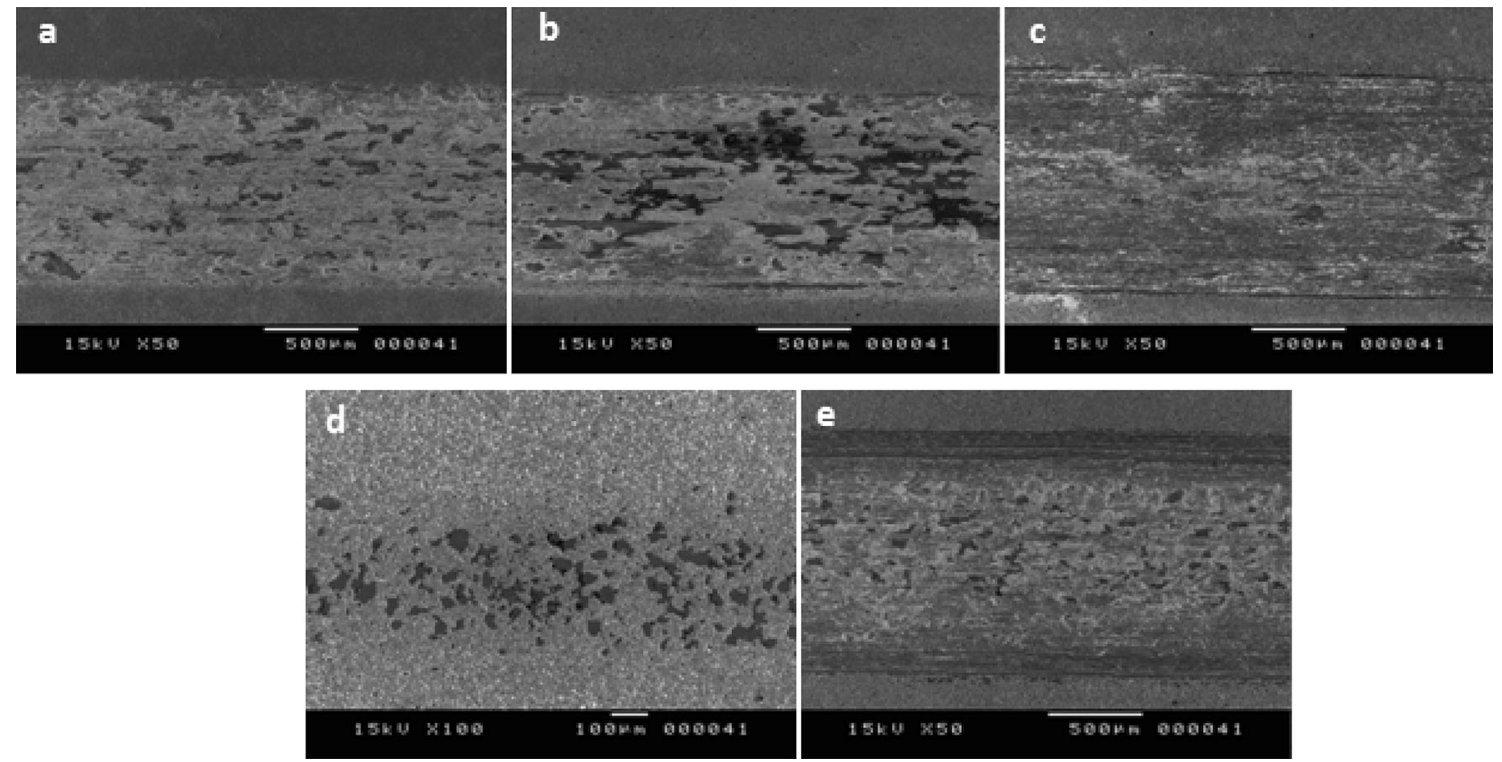

Fig. 12 SEM micrographs of wear track after 2000 sliding cycles of Ni composite coatings filled with different weight fraction of graphite: a pure, b $10 \%$, c $23 \%$, d $38 \%$, e $42 \%$ 


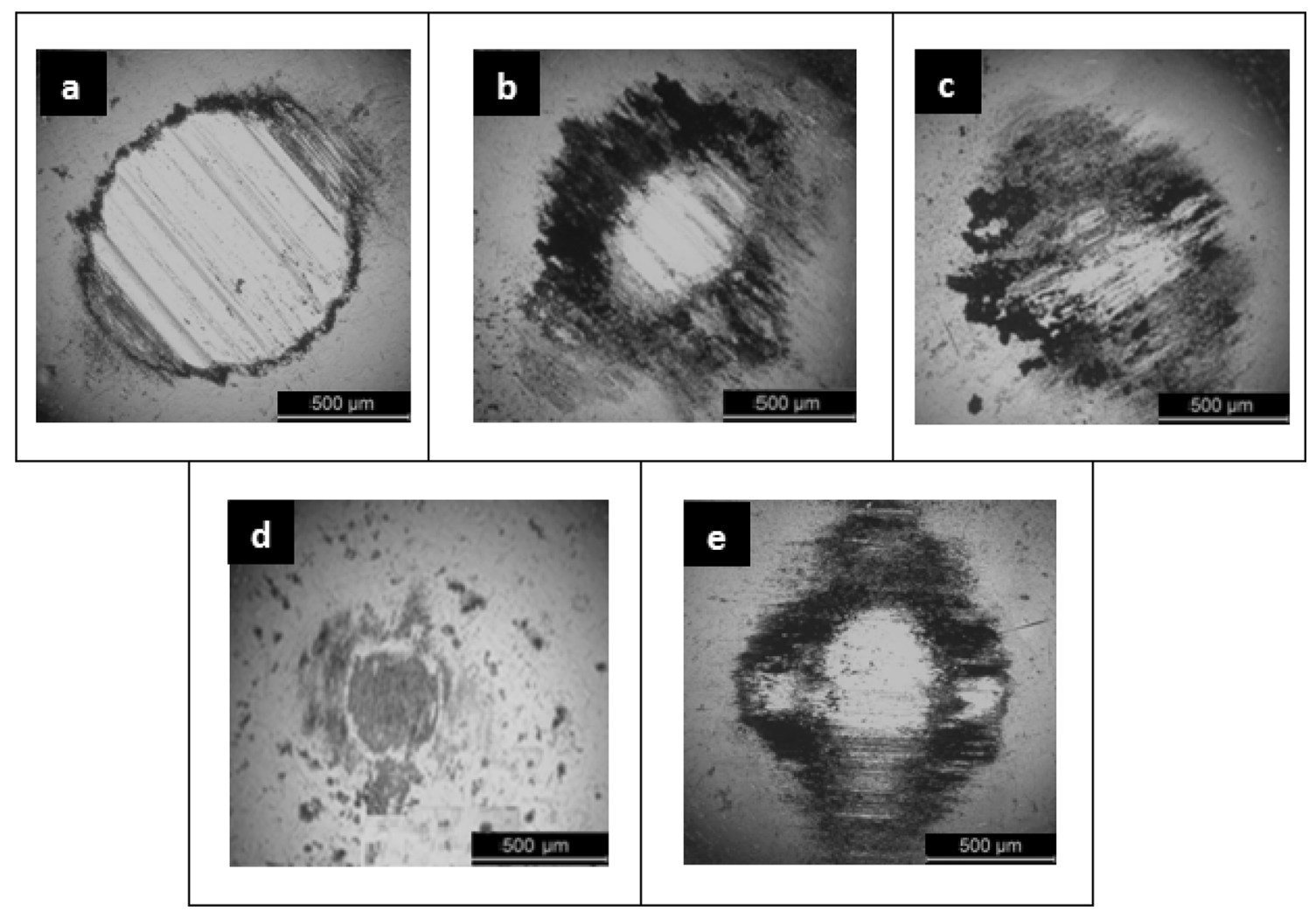

Fig. 13 Optical micrographs of the counterbody worn surface after 2000 sliding cycles against Ni composite coatings filled with different weight fraction of graphite: a pure, b $10 \%$, c $23 \%$, d $38 \%$, e $42 \%$

(Fig. 13d). This result confirms that the addition of graphite with optimal value results in making a self-lubricating coating. After the addition of $42 \mathrm{wt} \%$ of graphite to the coating (Fig. 13e), a discontinuous transfer film reappears on the counterface and a denuded zone is observed in the center of the transfer film, confirming that at this concentration, the detachment of particles easily take place and they act as abrasive particles in the contact zone.

\section{Conclusion}

In this study, Ni-graphite composite coatings were electrodeposited from typical watts bath with specific operating conditions which was found to minimize the level of internal stresses. Different weight fractions of graphite microparticles were considered. The microstructures and morphologies of the obtained coatings were explored using atomic absorption technique, SEM, OM, tactile profilometry and XRD. Concerning the micromechanical and tribological behaviors of $\mathrm{Ni}$-graphite coatings, they were analyzed with microhardness tester and linear reciprocation ball on plane tribometer. The following conclusions could be drawn:
- The weight percentage of particles in coatings increases as the concentration of graphite particles in the electrolytic bath increases.

- The coating surface roughness increases with the weight fraction of graphite.

- The coating's microhardness depends on the graphite particle amount. Indeed, the rise of this amount exhibits a notable decrease of microhardness, which is attributed to the sliding ability and soft nature of graphite particles.

- The stabilized COF value decreases as the graphite content in the Ni matrix increases. This behavior is ascribed to the development of solid self-lubricant layer on the wear track as well as transfer film on the counterface allowing an easy slippage between the layers of graphite due to its hexagonal structure.

- The wear volume loss of $\mathrm{Ni}$-graphite coatings decreases with the increase of the graphite fraction upto $38 \mathrm{wt} \%$ at which a continuous transfer film is formed on the steel counterface. Exceeding this optimal fraction, a discontinuous transfer film reappears and the volume loss re-increases.

- The optimal graphite concentration of $38 \mathrm{wt} \%$ provides the best condition to promote the solid lubricant layer stability and to maintain the Ni matrix integrity. 
Acknowledgements The authors gratefully acknowledge the help and support of Professor Mongi Feki from the Laboratory of Materials Engineering and Environment (National Engineering School of Sfax; Sfax; Tunisia).

\section{References}

1. Donnet C, and Erdemir A, Surf Coat Technol 180-181 (2004) 76.

2. Celis J P, Roos J R, Buelens C, and Franser J, Trans Inst Met Finish 69 (1991) 133.

3. Ding X Z, Zeng X T, He X Y, and Chen Z, Surf Coat Technol 205 (2010) 224

4. Cai B, Tan Y F, Tu Y Q, Wang X L, and Tan H, Trans Nonferrous Met Soc 21 (2011) 2426.

5. Chen J, Li J, Xiong D, He Y, Ji Y, and Qin Y, Appl Surf Sci 361 (2016) 49.

6. Gyawali G, Kim H S, Tripathi K, Kim T H, and Lee S W, J Mater Sci Technol 30(8) (2014) 796.

7. Guo C, Zuo Y, Zhao X, Zhao J, and Xiong J, Surf Coat Technol 202 (2008) 3385.

8. Praveen Kumar C M, Venkatesha T V, and Chandrappa K G, Surf Coat Technol 206 (2012) 2249.

9. Zhao H, Liu L, Hu W, and Shen B, Mater Des 28 (2007) 1374.

10. Mohammadi M, and Ghorbani M, J Coat Technol Res 8 (2011) 527.

11. Cardinal M F, Castro P A, Baxi J, Liang H, and Williams F J, Surf Coat Technol 204 (2009) 85.

12. Sun W, Tian M, Zhang P, Wei H, Hou G, and Wang Y, Trans Indian Inst Met 69(8) (2016) 1501.

13. Sajjadnejad M, Setoudeh N, Mozafari A, Isazadeh A, and Omidvar H, Trans Indian Inst Met 70(6) (2017) 1533.

14. Lecina E G, Urrutia I G, Diez J A, Salvo M, Smeacetto F, Gautier G, Seddon R, and Martin R, Electrochim Acta 54 (2009) 2556.

15. Góral A, Litynska-Dobrzynska L, and Kot M, J Mater Eng Perform 26(5) (2017) 2118.

16. Lekka M, Lanzutti A, Casagrande A, Leitenburge de C, Bonora P L, and Fedrizzi L, Surf Coat Technol 206 (2012) 3658.

17. Lapinsky J, Pletcher D, and Walsh F C, Surf Coat Technol 205 (2011) 5205.

18. Tang J J, Yang Q Z, Wang P, Wang Y, Zhao L, Fu Q Q, Han Z H, and Bai Y, Surf Coat Technol 252 (2014) 48.

19. Wu B, Yu X, Zhang B, and Xu B, Surf Coat Technol 202 (2008) 1975.
20. He X, Zhang X, Zhou X, and Fu Z, Adv Mater Res 150-151 (2011) 1546.

21. Suh P, Wear 25 (1973)111.

22. Wang Y L, Wan Y Z, Zhao S M, Tao H M and Dong X H, Surf Coat Technol 106(2-3) (1998) 162.

23. Güler E S, Konca E, Karakaya I, Surf Eng 30(2) (2014) 109.

24. Stein B, A Practical Guide to Understanding, Measuring and Controlling Stress in Electroformed Metals, AESF Electroforming Symposium, Las Vegas (1996).

25. Dennis J K, and Such T E, Nickel and Chromium Plating, (Ed) Woodhead publishing limited (1993).

26. Lowenheim F A, Brown H, and Knapf B B, Modern Electroplating, (Eds) John Wiley and sons, Toronto (1974) p 287.

27. Barrett R C, Nickel Plating from the Sulfamate bath, Forty-First Annual Convention of the American Electroplaters' Society, (1954).

28. Dini J W, The Materials Science of Coatings and Substrates, (Ed) N.J. Noyes publications, New Jersey (1993).

29. Laroche M A, and Mortier F, contrôle des revêtements électrolytiques et chimiques, (Ed) CETIM, France, 1989.

30. Wasekar N P, Madhavi Latha S, Ramakrishna M, Rao D S, and Sundararajan G, Mater Des 112 (2016) 140.

31. Guglielmi N, J Electrochem Soc 119 (1972) 1009.

32. Hou K H, Wang H T, Sheu H H, and Gerc M D, Appl Surf Sci 308 (2014) 372

33. Özkan S, Hapçı G, Orhan G, and Kazmanlı K, Surf Coat Technol 232 (2013) 734.

34. Ghorbani M, Mazaheri M, Khangholi K, and Kharazi Y, Surf Coat Technol 148 (2001) 71.

35. Ungàr T, Scr Mater 51 (2004) 777.

36. Borkar T and Harimkar S, Surf Eng 27 (2011) 524.

37. Srivastava M, William Grips V K, and Rajam K S, Appl Surf Sci 253 (2007) 3814.

38. Borkar T, and Harimkar S P, Surf Coat Technol 205 (2011) 4124.

39. Ghorbani M, Mazaheri M, and Afsher A, Surf Coat Technol 190 (2005) 32.

40. Cai B, Tan Y F, Tu Y Q, Wang X L, and Xu T, T Nonferr Metal Soc 21 (2011) 1741.

41. Nickchi T, Ghorbani M, Alfantazi A, and Farhat Z, Mater Des 32 (2011) 3548.

42. Sun W C, Zhang P, Zhao K, Tian M M, and Wang Y, Wear 342343 (2015) 172. 